\title{
Açaí (Euterpe oleracea Mart.) attenuates alcohol-induced liver injury in rats by alleviating oxidative stress and inflammatory response
}

\author{
JIANYU ZHOU ${ }^{1-3}$, JIANJUN ZHANG $^{2}, \mathrm{CHUN} \mathrm{WANG}^{2}$, SHENGSHENG QU ${ }^{2}$, YINGLI ZHU $^{2}$, \\ ZHIHUI YANG ${ }^{4}$ and LINYUAN WANG ${ }^{1}$
}

\author{
${ }^{1}$ Department of Pharmaceutics of Chinese Materia Medica, School of Chinese Materia Medica, Beijing University of \\ Chinese Medicine; ${ }^{2}$ Department of Traditional Chinese Clinical Pharmacology, School of Preclinical Medicine, \\ Beijing University of Chinese Medicine, Beijing 100029; ${ }^{3}$ Department of Traditional Chinese Medicine, \\ Chengde Medical University, Chengde, Hebei 067000, P.R. China; ${ }^{4}$ Department \\ of Psychiatry, University of Florida, Gainesville, FL 32608, USA
}

Received August 2, 2016; Accepted April 28, 2017

DOI: $10.3892 / \mathrm{etm} .2017 .5427$

\begin{abstract}
The present study aimed to investigate the therapeutic effects of Euterpe oleracea Mart. (EO) on alcoholic liver diseases (ALD). A total of 30 Wistar rats were randomly divided into three groups (10 rats per group), including alcohol group (alcohol intake), EO group (alcohol + EO puree intake) and control group (distilled water intake). The activity of superoxide dismutase (SOD) and alkaline phosphatase (ALP), alanine aminotransferase (ALT) and aspartate aminotransferase (AST) and the levels of cholesterol (CHO), triglyceride (TG), malondialdehyde (MDA) and glutathione (GSH) in the serum as well as the liver tissue levels of interleukin 8 (IL-8), tumor necrosis factor- $\alpha$ (TNF- $\alpha$ ) and transforming growth factor- $\beta$ (TGF- $\beta$ ) were measured. Histopathological changes in liver tissues were observed by hematoxylin and eosin staining. Reverse-transcription quantitative PCR analysis was performed for detecting the expression of nuclear factor (NF)- $\mathrm{\kappa B}$ and CD68. The results indicated that EO intake significantly decreased ALT, AST, ALP, TG and CHO as well as the hepatic index in alcohol-treated rats. In addition, EO treatment relieved alcohol-induced oxidative stress by decreasing the levels of MDA and TG, and increasing the activity of SOD and GSH levels. In addition, the expression of TNF- $\alpha$, TGF- $\beta$, IL- 8 , NF- $\kappa$ B and CD-68 in the liver were decreased by EO treatment. Furthermore, EO intake alleviated the histopathological liver damage, including severe steatosis
\end{abstract}

Correspondence to: Dr Linyuan Wang, Department of Pharmaceutics of Chinese Materia Medica, School of Chinese Materia Medica, Beijing University of Chinese Medicine, 11 East Beisanhuan Road, Chaoyang, Beijing 100029, P.R. China

E-mail: wangly@bucm.edu.cn

Key words: alcoholic liver disease, hepatotoxicity, Euterpe oleracea Mart, oxidative stress, inflammation and abundant infiltrated inflammatory cells. In conclusion, EO alleviated alcohol-induced liver injury in rats by alleviating oxidative stress and inflammatory response.

\section{Introduction}

Alcoholic liver disease (ALD) is the main cause of advanced liver disease and is associated with high mortality on a global level (1). The ALD-associated mortality rate was reported to be up to $3.8 \%$ throughout the world (1). In China, an increasing incidence of ALD was identified among hospitalized patients with liver diseases from 2.7 to $4.4 \%$ between 2000 and 2004 (2). The morphological features of ALD include steatosis, alcoholic hepatitis, fibrosis, cirrhosis and hepatocellular carcinoma (3). ALD is induced by long-term alcohol abuse and alcohol dependence (4). The deleterious effects of alcohol are mainly attributed to the massive production of reactive oxygen species (ROS) and acetaldehyde from ethanol metabolism $(5,6)$. Since oxidative stress and metabolite-induced inflammatory factors are involved in the development of ALD, specific anti-oxidants potentially blunt ethanol-induced oxidative stress and prevent this pathogenesis $(7,8)$.

During ethanol metabolism, ROS stimulate the activation of the nuclear factor- $\mathrm{\kappa B}(\mathrm{NF}-\mathrm{\kappa B})$ pathway in the liver, which in turn accelerates local synthesis of inflammatory mediators, including interleukin- 8 (IL-8), tumor necrosis factor- $\alpha$ (TNF- $\alpha$ ) and transforming growth factor- $\beta$ (TGF- $\beta$ ) (9-12). In addition, serum biochemical factors such as aspartate aminotransferase (AST), alanine aminotransferase (ALT), cholesterol (CHO) and alkaline phosphatase (ALP) are biomarkers for the progression of ALD (13-15). These inflammatory factors lead to cytokine imbalance and immune disorders, which further impairs liver function. Thus, any agent with anti-oxidative (or anti-inflammatory) abilities may potentially attenuate alcohol-induced liver injury.

Euterpe oleracea Mart. (EO), also known as Açaí or jucara, is a fruit widely consumed by the local population 
of the Amazon region (16). EO has been found to contain high levels of phytochemicals that exhibit anti-oxidant and anti-inflammatory activities (16-18). Furthermore, EO has been found to have antitumor activity and improve cardiac dysfunction $(19,20)$. However, to the best of our knowledge, the therapeutic effect of EO in ALD has remained elusive. In the present study, the influence of EO on hepatic oxidative and inflammatory factors were assessed. Furthermore, the mRNA levels of NF- $\kappa \mathrm{B}$ and CD-68 were evaluated in an attempt to elucidate the mode of action of EO on ALD.

\section{Materials and methods}

Plant material. EO puree was purchased from Belalaçá Polpas de Frutas Indústria e Comércio Ltda (cat no. PA-COE-01/2011; Castanhal, Brazil). In order to preserve the nutritional components and organoleptic qualities, EO puree had been prepared within $20 \mathrm{~h}$ of harvesting. After the skin and seeds were discarded, the watery pulp was processed for puree preparation. Each 100-g portion of EO puree contained $0.035 \mathrm{~g}$ procyanidine, as determined by an inspection institution (report ID, E0819002201D; Pony Testing International Group, Beijing, China). The prepared EO puree was composed of $10 \%$ solid body and $90 \%$ liquid. Subsequent to obtainment, EO puree was stored at $-20^{\circ} \mathrm{C}$ for further analysis.

Animals. A total of 30 Wistar rats (weight, 220-240 g; age, 7 weeks) were purchased from SPF Biotechnology Co., Ltd. (Beijing, China). All of the animals were housed in the Experimental Animal Lab of Beijing University of Chinese Medicine (Beijing, China) under a 12-h light/dark cycle with ad libitum access to water and standard food, and were allowed to adapt to the laboratory conditions for one week. Ethical approval was obtained from the Animal Care Committee of Beijing University of Chinese Medicine (Beijing, China). All of the animal experiments were performed according to the Guide for the Care and Use of Laboratory Animals (Ministry of Science and Technology of China, 2006). Rats were randomly divided into three groups (10 rats per group), including alcohol group (alcohol intake), EO group (alcohol + EO puree intake) and control group (distilled water intake). In the first week, rats in the alcohol group and the EO group were treated with alcohol ( $56 \% ; 0.8 \mathrm{ml} / 100 \mathrm{~g})$ daily by oral gavage in the morning. The amount of alcohol was then increased by $0.1 \mathrm{ml}$ every other week until the 8 th week (1.5 ml/100 $\mathrm{g}$ in the 8 th week) (21). In the control group, rats were given the same volume of distilled water once daily in the morning. In the afternoon, EO puree $(1 \mathrm{ml} / 100 \mathrm{~g}$ ) was administered to rats by oral gavage in the EO group, while rats in the control and alcohol groups received the same volume of distilled water. All of the treatments were maintained for 8 consecutive weeks.

Serum biochemical marker assay. After the rats were deeply anesthetized with chloral hydrate $(350 \mathrm{mg} / \mathrm{kg}$, intraperitoneally; Beijing Chemical Works, Beijing, China), blood samples were collected from abdominal aortas. Serum was collected by centrifugation at $300 \mathrm{x}$ g for $15 \mathrm{~min}$ at $4^{\circ} \mathrm{C}$ and stored at $-80^{\circ} \mathrm{C}$ for further analysis.

The levels of ALT and AST in serum were measured by using commercial assay kits (cat nos. C009-1 and C010-1;
Nanjing Jiancheng Bioengineering Institute, Nanjing, China) and colorimetrically determined with a 752-C ultraviolet-visible spectrophotometer (Shanghai Third Analytical Instrument Factory, Shanghai, China). The serum alkaline phosphatase (ALP) activity was quantified using a commercial assay kit (cat no. A059-1; Nanjing Jian Cheng Bioengineering Institute) and a Microlab F.A.M.E automated microplate reader (WD-2102A; Beijing Liuyi Instrument Biotechnology Co., Ltd., Beijing, China). The serum triglyceride (TG) and $\mathrm{CHO}$ levels were quantified using commercial kits (cat nos. Y015 and Y014; Beijing Beihuakangtai Clinical Reagent Co., Ltd., Beijing, China) by using an A6 Semi-automatic Biochemistry Analyzer (Beijing Shining Sun Tech. Co., Ltd., Beijing, China).

Inflammatory cytokine measurement. The serum levels of IL- 8 , TNF- $\alpha$ and TGF- $\beta$ were determined with immunoassay kits (cat nos. HY-H0008, HY-H0019 and HY-H0022; Beijing Sino-UK Institute of Biological Technology, Beijing, China) by using a R-911 automatic radioimmunity analyzer (USTC Holdings Co., Ltd., Hefei, China).

Histopathological examination and assessment. Following anesthesia with $10 \%$ chloral hydrate $(5 \mathrm{ml} / \mathrm{kg})$, the experimental rats were sacrificed and the liver tissues were isolated and weighed to determine the hepatic index as follows: Hepatic index $=$ liver weight/animal weight $\mathrm{x} 100$. Liver tissues with the approximate dimensions of $2 \times 2 \times 2 \mathrm{~mm}^{3}$ were fixed with $4 \%$ paraformaldehyde and embedded in paraffin. Paraffin sections $(5 \mu \mathrm{m})$ were stained with hematoxylin and eosin, and observed under a light microscope (magnification, x400; Nikon Eclipse Ti-SR; Nikon, Tokyo, Japan).

To determine the protein expression of CB68, the liver sections were deparaffinized with xylene, dehydrated in a graded series of ethanol and washed with distilled water. The sections were treated with $3 \% \mathrm{H}_{2} \mathrm{O}_{2}$ for $25 \mathrm{~min}$, followed by blocking with EDTA solution buffer for antigen retrieval by microwave heating. Then, the sections were incubated with anti-CD68 antibody (1:100 dilution; cat no. GB13067-M; Goodbio Technology Co., Ltd., Wuhan, China) at $4^{\circ} \mathrm{C}$ overnight and horseradish peroxidase-conjugated sheep anti-mouse antibody (1:200; cat no. 074-1806; KPL, Inc., Gaithersburg, $\mathrm{MD}, \mathrm{USA}$ ) at $37^{\circ} \mathrm{C}$ for $10 \mathrm{~min}$. Then, the sections were stained with 3,3'-diaminobenzidine (Dako Real DAB+ Chromogen, K5007; Agilent Technologies, Inc., Santa Clara, CA, USA) according to the manufacturer's instructions. CD68-positive cells were observed under a microscope and quantified using the Image-Pro Plus 6.0 imaging analysis system (Media Cybernetics, Rockville, MD, USA).

Analysis of anti-oxidative activity. The liver tissues $(0.2 \mathrm{~g})$ were homogenized with $1.8 \mathrm{ml}$ ice-cold physiological saline and centrifuged at $1,000 \mathrm{x}$ for $10 \mathrm{~min}$ at $4^{\circ} \mathrm{C}$. The supernatant was collected for further analysis. The hepatic tissue activity of superoxide dismutase (SOD) as well as the levels of anti-oxidant scavengers glutathione (GSH) and malondialdehyde (MDA) were determined using commercial assay kits (cat nos. A006 and A003-1; Nanjing Jiancheng Bioengineering Institute) with a 752-C ultraviolet-visible spectrophotometer. The content of TG in liver tissues was measured by using a TG assay kit (cat no. A110-2; Nanjing Jiancheng Bioengineering 
A

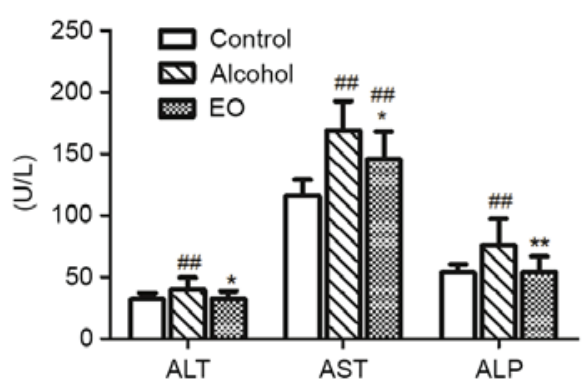

B

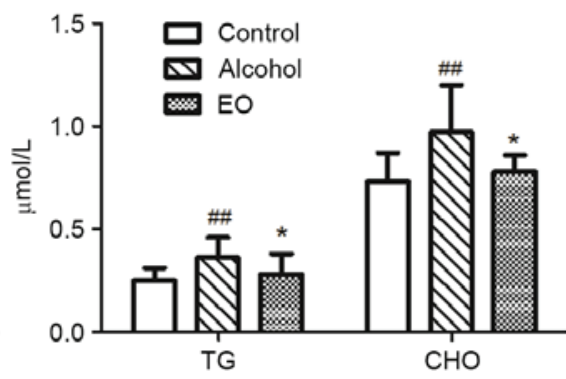

C

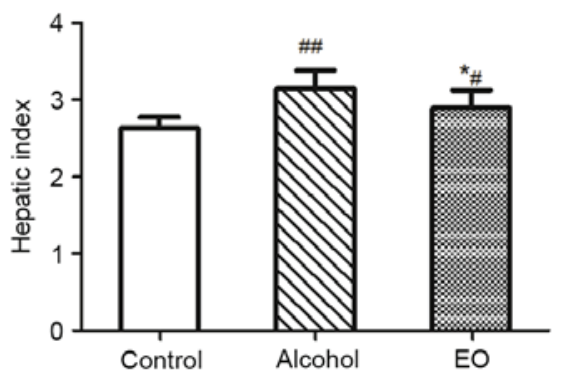

Figure 1. Effects of EO on alleviated chronic alcoholic liver injury in rats. (A) Activities of ALT, AST and ALP in the serum of rats. (B) TG and CHO concentrations in the serum; (C) Hepatic index. Values are expressed as the mean \pm standard deviation $(\mathrm{n}=10)$. ${ }^{\#} \mathrm{P}<0.05$, ${ }^{\# \#} \mathrm{P}<0.01 \mathrm{compared}$ with control group. ${ }^{*} \mathrm{P}<0.05,{ }^{* *} \mathrm{P}<0.01$ compared with alcohol group. EO, Euterpe oleracea Mart.; TG, triglyceride; ALT, alanine aminotransferase; AST, aspartate aminotransferase; ALP, alkaline phosphatase; $\mathrm{CHO}$, cholesterol.

Table I. Sequences of primers targeting rat genes used for polymerase chain reaction.

Primer Sequence

$\beta$-actin forward 5'-CGTTGACATCCGTAAAGACCTC-3' $\beta$-actin reverse 5 '-TAGGAGCCAGGGCAGTAATCT-3' $\mathrm{NF}-\kappa \mathrm{B}$ forward 5'-CACCAAAGACCCACCTCACC-3' NF- $\kappa$ B reverse 5'-CCGCATTCAAGTCATAGTCCC-3' CD68 forward 5'-GCCTCTCTGTATTGAACCCGAAC-3' CD68 reverse 5'-AAGGACACATTGTATTCCACTGCC-3

$\mathrm{NF}-\kappa \mathrm{B}$, nuclear factor- $\mathrm{\kappa} \mathrm{B} ; \mathrm{CD}$, cluster of differentiation.

Institute) according to the manufacturer's instructions with an A6 Semi-automatic Biochemistry Analyzer.

Reverse-transcription quantitative polymerase chain reaction ( $R T-q P C R$ ) assay. Total RNA of liver tissues was extracted using TRIzol reagent (Invitrogen; Thermo Fisher Scientific, Inc., Waltham, MA, USA) according to the manufacturer's instructions. Complementary (c)DNA was generated using the RevertAid First-Strand cDNA Synthesis kit (cat no. K1622; Thermo Fisher Scientific, Inc.) and amplified using Fast Start Universal SYBR-Green Master Mix (Rox; cat no. 04913914 001; Roche Diagnostics, Basel, Switzerland) on a 7300 Real-Time PCR system (Applied Biosystems, Thermo Fisher Scientific, Inc.). The thermal cycling conditions included denaturation at $95^{\circ} \mathrm{C}$ for $10 \mathrm{~min}$, followed by 40 cycles amplification of $95^{\circ} \mathrm{C}$ for $15 \mathrm{sec}$ and $60^{\circ} \mathrm{C}$ for $60 \mathrm{sec}$. The specific primers for $\beta$-actin, $\mathrm{NF}-\kappa \mathrm{B}$ and CD68 were obtained from Invitrogen (Thermo Fisher Scientific, Inc.) and the sequences of are listed in Table I. The relative mRNA expression was analyzed using the $2^{-\Delta \Delta C q}$ method by normalizing to $\beta$-actin mRNA expression as the internal control (22).

Statistical analysis. Values are expressed as the mean \pm standard deviation and. Statistical analysis was performed using SPSS 17.0 software (SPSS, Inc., Chicago, IL, USA). One-way analysis of variance was performed for comparisons between groups, followed by post-hoc comparisons using Dunnett's t-test. $\mathrm{P}<0.05$ was considered to indicate a statistically significant difference.

\section{Results}

Effect of EO on ALT, AST, ALP, TG, CHO and hepatic index in serum of rats with $A L D$. Compared with those in the control group, the levels of ALT, AST, ALP, TG and CHO in the serum of rats of the alcohol group were significantly increased $(\mathrm{P}<0.01$; Fig. 1A and B). Rats in the EO group had significantly lower serum levels of ALT, AST, ALP, TG and CHO in compared with those in the alcohol group (ALT, 32.88 \pm 6.43 vs. $41.2 \pm 8.85 \mathrm{U} / 1, \mathrm{P}<0.05 ; \mathrm{AST}, 144.63 \pm 23.65$ vs. $168.27 \pm 25.68 \mathrm{U} / 1$, $\mathrm{P}<0.05$; ALP, 53.17 \pm 14.31 vs. 76.41 $\pm 21.75 \mathrm{U} / 1, \mathrm{P}<0.01 ; \mathrm{TG}$, $0.28 \pm 0.1$ vs. $0.37 \pm 0.09 \mu \mathrm{mol} / 1, \mathrm{P}<0.05 ; \mathrm{CHO}, 0.78 \pm 0.08$ vs. $0.97 \pm 0.23 \mu \mathrm{mol} / 1, \mathrm{P}<0.05)$. Compared with that in the control group, the hepatic index in the alcohol group was significantly increased $(2.62 \pm 0.15$ vs. $3.13 \pm 0.24, \mathrm{P}<0.01)$, while it obviously declined after EO treatment $(2.88 \pm 0.23, \mathrm{P}<0.05$; Fig. $1 C)$.

Pathological changes after treatment. The pathological changes of liver tissues are presented in Fig. 2. Regular lobular architecture with central veins and radiating hepatic cords were observed in the livers of control rats (Fig. 2A). However, liver sections from the alcohol group displayed severe steatosis and abundant infiltrated inflammatory cells (Fig. 2B). These histopathological changes were substantially alleviated by EO treatment (Fig. 2C).

Effect of EO on GSH, MDA, TG and the activity of SOD induced by alcohol in liver tissues. To investigate the effects of the EO on alcohol-induced oxidative stress, the content of GSH, MDA and TG as well as the activity of SOD in liver tissues were evaluated. The level of GSH and the activity of the anti-oxidant enzyme SOD in liver tissues were significantly reduced in alcohol-treated rats ( $\mathrm{P}<0.01$ vs. control; Fig. 3A and $\mathrm{B}$ ). Furthermore, the content of MDA was significantly increased in the alcohol-treated rats compared with that in the controls $(\mathrm{P}<0.01$; Fig. 3C). A significant increase of TG was also found in rats of the alcohol group $(\mathrm{P}<0.01$ vs. control; Fig. 3D). These alterations were significantly restored by the administration of $\mathrm{OE}(\mathrm{P}<0.05$ vs. alcohol group). 
A

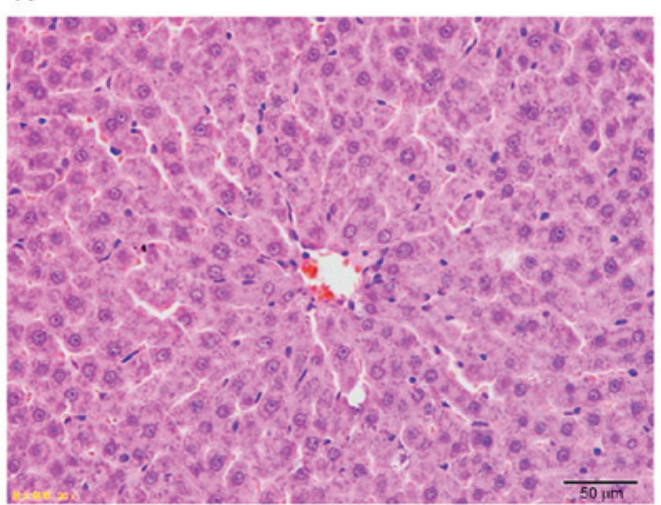

B

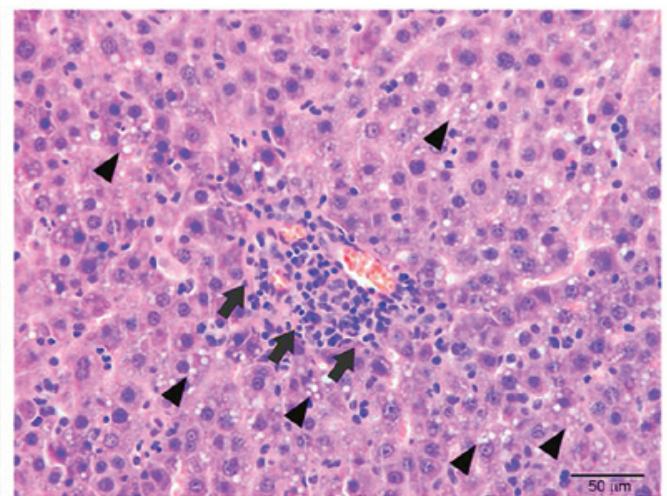

C

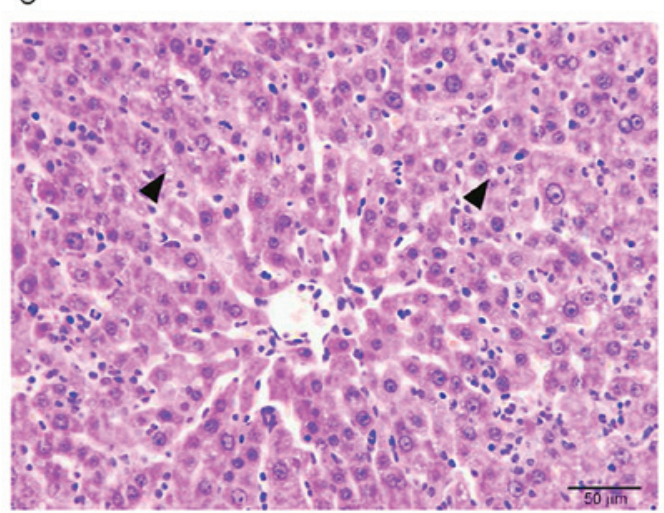

Figure 2. Effects of EO on pathological changes in hepatic tissues. (A) Control group; (B) alcohol group; (C) EO group. Arrows indicate the infiltrated inflammatory cells and arrowheads indicate steatosis (magnification, $\mathrm{x} 400$; scale bar, $50 \mu \mathrm{m}$; hematoxylin and eosin staining). EO, Euterpe oleracea Mart.
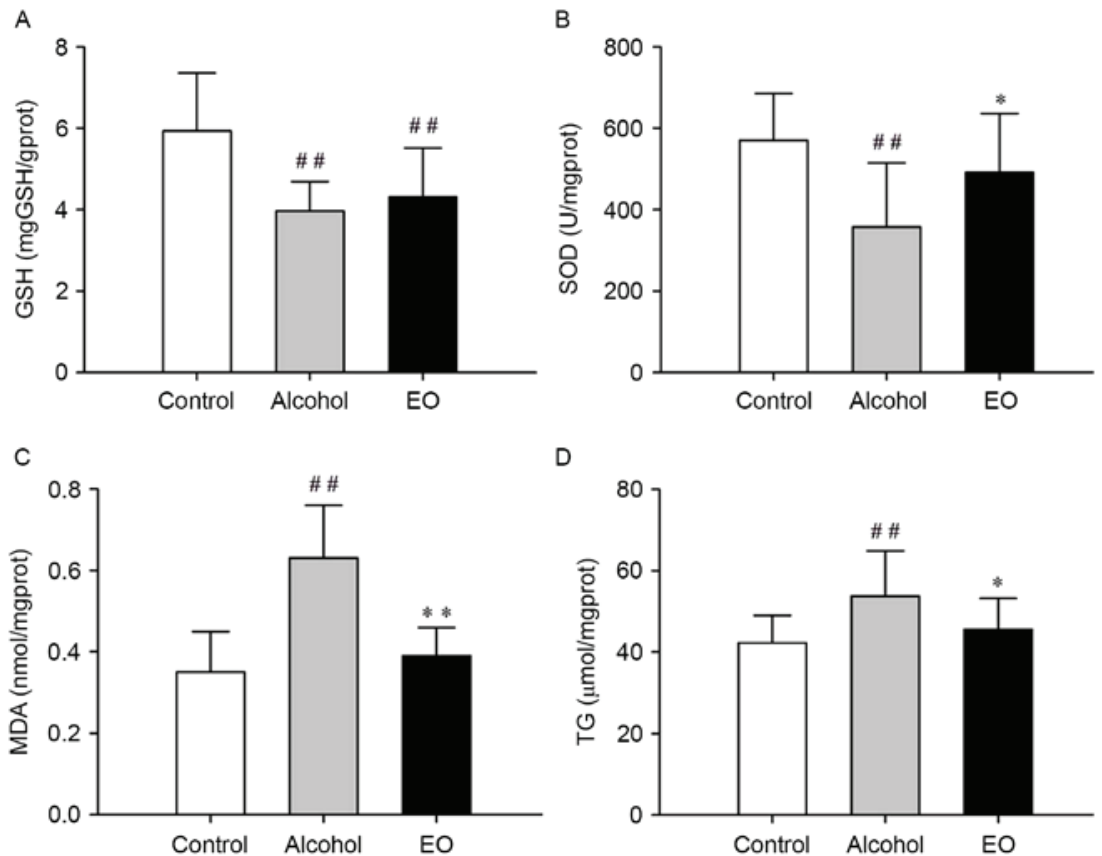

Figure 3. Effects of EO on lipid peroxidation and anti-oxidants. (A) Levels of GSH; (B) activity of SOD; (C) levels of MDA; (D) levels of TG in hepatic tissues. Values are expressed as the mean \pm standard deviation $(\mathrm{n}=10)$. ${ }^{\# /} \mathrm{P}<0.01$, compared with control group. ${ }^{*} \mathrm{P}<0.05,{ }^{* *} \mathrm{P}<0.01$, compared with alcohol group. EO, Euterpe oleracea Mart.; GSH, glutathione; SOD, superoxide dismutase; MDA, malondialdehyde; TG, triglyceride; prot, protein.

Effect of EO on hepatic inflammatory markers. The levels of the inflammatory cytokines TNF- $\alpha$, TGF- $\beta$ and IL- 8 in the liver were determined in the present study. As presented in Fig. 4, the levels of TNF- $\alpha$, TGF- $\beta$ and IL-8 were 


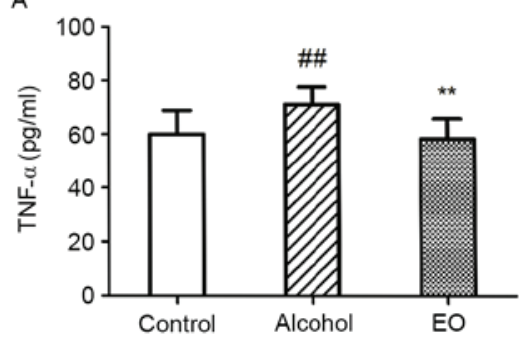

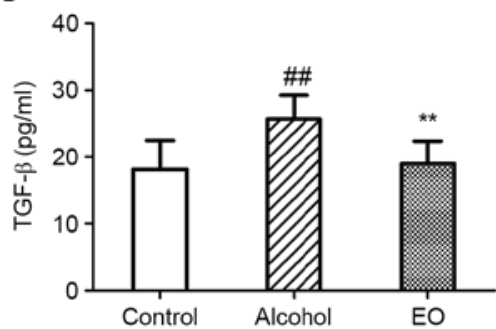

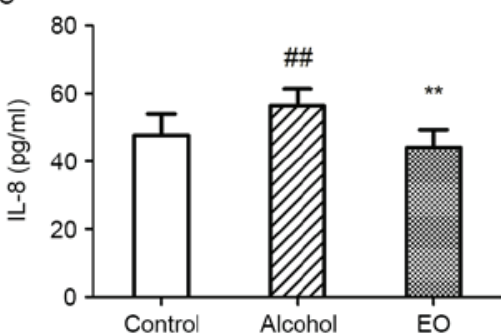

Figure 4. Effects of EO on inflammatory cytokine levels in the serum of rats. (A) TNF- $\alpha$ concentration; (B) TGF- $\beta$ concentration; (C) IL-8 concentration. Values are expressed as the mean \pm standard deviation $(\mathrm{n}=10) .{ }^{\# *} \mathrm{P}<0.01$, compared with control group. ${ }^{* *} \mathrm{P}<0.01$, compared with alcohol group. EO, Euterpe oleracea Mart.; TNF, tumor necrosis factor; TGF, transforming growth factor; IL, interleukin.

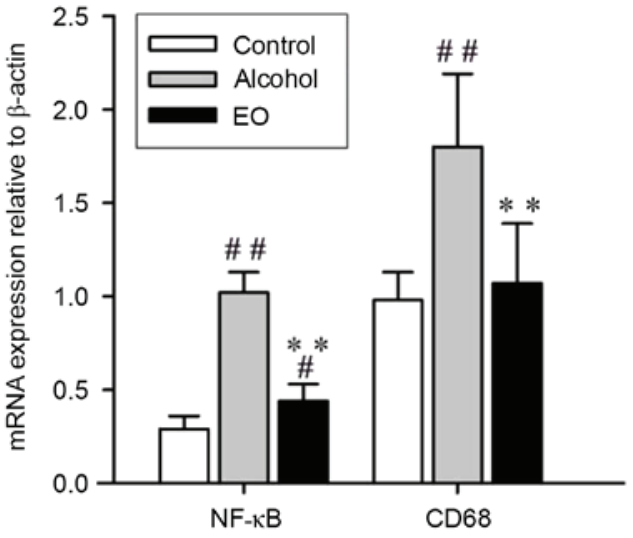

Figure 5. Effects of EO on mRNA levels of NF-kB and CD68 in hepatic tissue. Values are expressed as the mean \pm standard deviation $(\mathrm{n}=6) .{ }^{*} \mathrm{P}<0.05$, ${ }^{\# \#} \mathrm{P}<0.01$, compared with control group. ${ }^{* *} \mathrm{P}<0.01$, compared with alcohol group. EO, Euterpe oleracea Mart.; NF, nuclear factor.

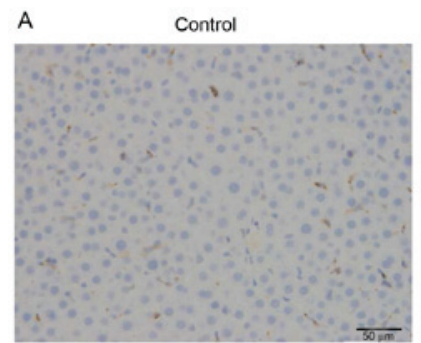

EO
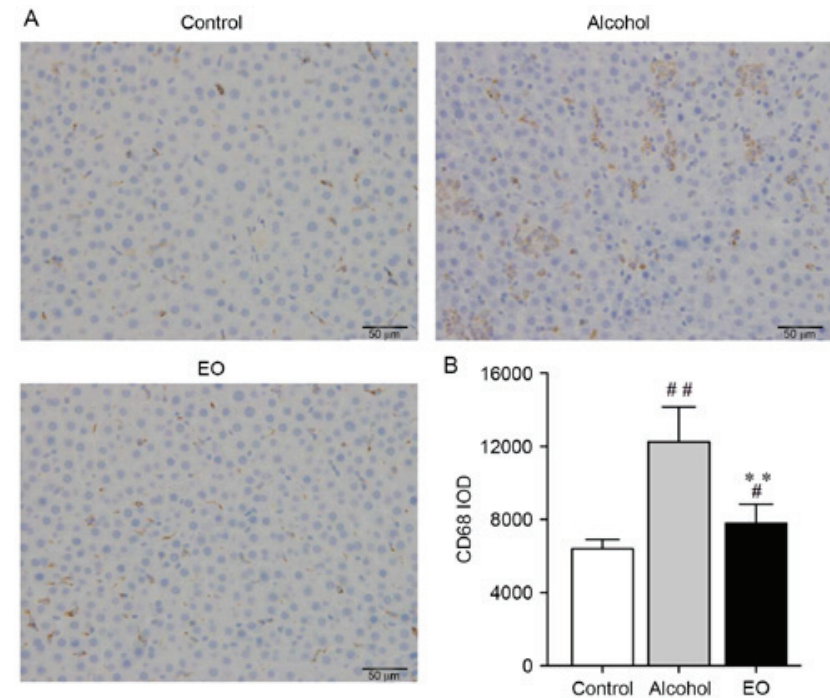

Figure 6. Effects of EO on expression levels of CD68 in rat livers with alcoholic injury. (A) Photomicrograph of hepatic tissue (positive staining for CD68 is indicated by brown or tan cytoplasm; scale bar, $50 \mu \mathrm{m}$ ); (B) IOD value of CD68. Values are expressed as the mean \pm standard deviation $(n=6)$. ${ }^{\#} \mathrm{P}<0.05,{ }^{\# \#} \mathrm{P}<0.01$, compared with control group. ${ }^{* *} \mathrm{P}<0.01$, compared with alcohol group. IOD, integrated optical density; EO, Euterpe oleracea Mart.

significantly elevated in the alcohol group compared with those in the control group $(\mathrm{P}<0.01)$, which was significantly inhibited by $\mathrm{EO}$ treatment $(\mathrm{P}<0.01$ vs. alcohol group).
Effect of $E O$ on $N F-\kappa B$ and $C D-68$. The results on the mRNA expression levels of NF- $\kappa \mathrm{B}$ and CD-68 are displayed in Fig. 5. Compared with those in the control group, the mRNA expression levels of NF- $\kappa \mathrm{B}$ and CD-68 were significantly increased by alcohol treatment $(1.02 \pm 0.11$ vs. $0.29 \pm 0.07, \mathrm{P}<0.01$; $1.8 \pm 0.39$ vs. $0.98 \pm 0.15, \mathrm{P}<0.01)$, which was significantly attenuated by EO treatment $(0.44 \pm 0.09$ vs. $1.02 \pm 0.11, \mathrm{P}<0.01$; $1.07 \pm 0.32$ vs. $1.8 \pm 0.39, \mathrm{P}<0.01$, respectively) Compared with that in the control group, the protein expression of CD68 was significantly increased in the alcohol group $(\mathrm{P}<0.01)$, which was significantly inhibited in the EO group $(\mathrm{P}<0.05$ vs. alcohol group; Fig. 6).

\section{Discussion}

ALD is a major cause of chronic liver disease and has resulted in critical personal health hazards and serious public health burdens worldwide (23). Development of novel therapies has improved the treatment of ALD, which mainly includes anti-oxidant, anti-inflammatory and anti-TNF- $\alpha$ therapy. However, the efficacy of these therapies remains controversial. EO is a fruit from the Amazon region and has been widely studied for its anti-oxidant and anti-inflammatory capacity (24). However, to the best of our knowledge, the therapeutic potential of EO for ALD has remained to be investigated and was therefore explored by the present study.

For the development of alcoholic liver injury, oxidative stress was reported to be crucial $(25,26)$. Oxidative stress was originally defined as the disequilibrium between oxidants and anti-oxidants in biological systems, which then leads to lipid peroxidation (27). A previous study showed that overproduction of ROS induced by alcohol metabolism may result in GSH depletion, decreasing anti-oxidant activities and elevating lipid peroxidation (28). MDA, an end-product of lipid peroxidation, is often used as an indicator of oxidative damage (29). The accumulation of TG has been regarded as a marker for steatosis (30). A study by de Oliveira et al (31) suggested that Açaí seed extract significantly reduced the hepatic expression of lipogenic proteins, such as sterol regulatory element-binding transcription factor 1c (SREBP-1c) and hydroxymethylglutaryl-CoA (HMGC-CoA) induced by a high-fat diet. In the present study paper, lipid peroxidation-associated proteins such as TG and MDA were found to be significantly reduced by OE. Thus, OE may relieve the ALD by preventing lipid peroxidation.

Anti-oxidant scavengers such as GSH are commonly used for the evaluation of anti-oxidant activities (32). In addition, 
SOD has been implicated in inflammatory diseases and oxidative stress $(33,34)$. Balasubramaniyan et al $(35)$ demonstrated that the level of MDA in the liver is increased under the enhancement of oxidative stress in mice. The results of the present study revealed that the liver tissues of rats with ALD, the content of GSH and SOD was significantly decreased, which was inhibited by the administration of OE, suggesting that $\mathrm{OE}$ treatment increased anti-oxidant activities in liver tissues. All of the above indicated that OE inhibited ROS generation in hepatocytes.

The association between the levels of certain factors in serum and liver failure has been previously reported $(36,37)$. Zeng et al (8) reported that the leakage of ALT and AST into the blood indirectly reflected liver failure caused by ALD. Li et al (38) indicated that in mice with alcohol-induced liver injury, pre-treatment with Platycodin D for 7 consecutive days significantly and dose-dependently inhibited the elevation of serum ALT and AST to near basal levels. In the present study, EO treatment significantly decreased the content of ALT and AST in the serum of alcohol-treated rats. In addition, the present study demonstrated an accumulation of ALP, ALT, TG and $\mathrm{CHO}$ in the serum after acute alcohol exposure. However, EO effectively inhibited alcohol-induced increases of serum CHO, ALP, ALT and TG. Based on these serum parameters, EO was demonstrated to be a potent preventive agent against ALD.

The results of the present study further demonstrated that the expression of TNF- $\alpha$, TGF- $\beta$, IL- $8, N F-\kappa B$ and CD-68 in liver tissues was decreased by EO treatment. TNF- $\alpha$, IL- $1 \beta$ and IL-6, secreted by Kupffer cells and peripheral blood monocytes, are three important inflammatory cytokines involved in ALD (39). Corticosteroids are considered to be the mainstay of treatment for alcoholic hepatitis by decreasing the levels of inflammatory cytokines such as TNF- $\alpha$ and IL-8 (40). However, available results on corticosteroid treatment are conflicting with regard to drug resistance. In the present study, EO intake significantly decreased the liver concentrations of TNF- $\alpha$, TGF- $\beta$ and IL- $8(\mathrm{P}<0.05)$, while no significant changes were observed in IL- 6 levels (data not shown). This result indicated that EO had a significant effect on inhibiting inflammation of ALDs by targeting TNF- $\alpha$, TGF- $\beta$ and IL-8. In addition, the histological data suggested that liver sections from the alcohol group displayed severe steatosis and abundant infiltrated inflammatory cells, which were substantially alleviated by EO treatment. Based on these findings, it was speculated that EO inhibited the inflammation in ALD by reducing the infiltration of inflammatory cells.

$\mathrm{NF}-\kappa \mathrm{B}$ is involved in an important signaling pathway responsible for the formation of oxidative and inflammatory reactants (41-43). A previous study revealed that maslinic acid intake led to the downregulation of hepatic protein expression of NF- $\kappa \mathrm{B}$ in alcohol-induced ALD (44). Based on the result of the present study that the expression of NF- $\kappa \mathrm{B}$ and CD-68 was decreased in the EO group compared with that in the alcohol group, it was speculated that EO exerted hepatoprotective effects by decreasing the production of downstream oxidative and inflammatory factors to finally alleviate alcohol-induced hepatotoxicity.

Despite the $\mathrm{NF}-\kappa \mathrm{B}$ pathway having a key role in the pathogenesis of ALD, the present study was limited to the measurement of the protein expression of $\mathrm{NF}-\kappa \mathrm{B}$ and the downstream molecules of the $\mathrm{NF}-\kappa \mathrm{B}$ signaling pathway. Furthermore, the effect of OE on the lipid content remains to be fully clarified and lipogenic proteins, such as SREBP-1c and HMGC-CoA, should be measured.

In conclusion, OE intake alleviated chronic alcoholic liver injury in rats by attenuating oxidative stress and the inflammatory response. These results implied that due to its anti-oxidative and anti-inflammatory features, OE may be applied for the treatment of ALD. However, further study is warranted.

\section{Acknowledgements}

The results of the present study were in part presented at the 2015 Annual Meeting of the American Society of Pharmacognosy, USA, 25-29 July 2015 (no. PX39; abstract DOI, 10.1055/s-0035-1556483).

\section{References}

1. Rehm J, Mathers C, Popova S, Thavorncharoensap M, Teerawattananon Y and Patra J: Global burden of disease and injury and economic cost attributable to alcohol use and alcohol-use disorders. Lancet 373: 2223-2233, 2009.

2. Fan JG: Epidemiology of alcoholic and nonalcoholic fatty liver disease in China. J Gastroenterol Hepatol 28 (Suppl 1): S11-S17, 2013.

3. Lieber CS: Alcoholic fatty liver: Its pathogenesis and mechanism of progression to inflammation and fibrosis. Alcohol 34: 9-19, 2004

4. Gramenzi A, Caputo F, Biselli M, Kuria F, Loggi E, Andreone P and Bernardi M: Review article: Alcoholic liver disease-pathophysiological aspects and risk factors. Aliment Pharmacol Ther 24: 1151-1161, 2006.

5. Tang CC, Huang HP, Lee YJ, Tang YH and Wang CJ: Hepatoprotective effect of mulberry water extracts on ethanol-induced liver injury via anti-inflammation and inhibition of lipogenesis in C57BL/6J mice. Food Chem Toxicol 62: 786-796, 2013

6. Xu T, Zheng L, Xu L, Yin L, Qi Y, Xu Y, Han X and Peng J: Protective effects of dioscin against alcohol-induced liver injury. Arch Toxicol 88: 739-753, 2014.

7. Liu H, Qi X, Cao S and Li P: Protective effect of flavonoid extract from Chinese bayberry (Myrica rubra Sieb. et Zucc.) fruit on alcoholic liver oxidative injury in mice. J Nat Med 68: 521-529, 2014.

8. Zeng T, Guo FF, Zhang CL, Zhao S, Dou DD, Gao XC and Xie KQ: The anti-fatty liver effects of garlic oil on acute ethanol-exposed mice. Chem Biol Interact 176: 234-242, 2008.

9. McClain CJ, Song Z, Barve SS, Hill DB and Deaciuc I: Recent advances in alcoholic liver disease. IV. Dysregulated cytokine metabolism in alcoholic liver disease. Am J Physiol Gastrointest Liver Physiol 287: G497G502, 2004.

10. Szuster-Ciesielska A, Mizerska-Dudka M, Daniluk J and Kandefer-Szerszen M: Butein inhibits ethanol-induced activation of liver stellate cells through TGF- $\beta, N F \kappa B, p 38$, and JNK signaling pathways and inhibition of oxidative stress. J Gastroenterol 48: 222-237, 2013.

11. Zima T and Kalousová M: Oxidative stress and signal transduction pathways in alcoholic liver disease. Alcohol Clin Exp Res 29 (11 Suppl): S110-S115, 2005.

12. Horiguchi N, Wang L, Mukhopadhyay P, Park O, Jeong WI, Lafdil F, Osei-Hyiaman D, Moh A, Fu XY, Pacher P, et al: Cell type-dependent pro- and anti-inflammatory role of signal transducer and activator of transcription 3 in alcoholic liver injury. Gastroenterology 134: 1148-1158, 2008.

13. Mari M, Morales A, Colell A, Garcia-Ruiz C and Fernández-Checa JC: Mitochondrial cholesterol accumulation in alcoholic liver disease: Role of ASMase and endoplasmic reticulum stress. Redox Biol 3: 100-108, 2014.

14. Gurung RB, Purbe B, Gyawali P and Risal P: The ratio of aspartate aminotransferase to alanine aminotransferase (AST/ALT): The correlation of value with underlying severity of alcoholic liver disease. Kathmandu Univ Med J (KUMJ) 11: 233-236, 2013. 
15. Lai CL, Ng RP and Lok AS: The diagnostic value of the ratio of serum gamma-glutamyl transpeptidase to alkaline phosphatase in alcoholic liver disease. Scand J Gastroenterol 17: 41-47, 1982.

16. Lichtenthäler R, Rodrigues RB, Maia JG, Papagiannopoulos M, Fabricius $\mathrm{H}$ and Marx F: Total oxidant scavenging capacities of Euterpe oleracea Mart. (Açaí) fruits. Int J Food Sci Nutr 56: 53-64, 2005.

17. Pacheco-Palencia LA, Mertens-Talcott $S$ and Talcott ST: Chemical composition, antioxidant properties, and thermal stability of a phytochemical enriched oil from Acai (Euterpe oleracea Mart.). J Agric Food Chem 56: 4631-4636, 2008.

18. Moura RS, Ferreira TS, Lopes AA, Pires KM, Nesi RT, Resende AC, Souza PJ, Silva AJ, Borges RM, Porto LC and Valenca SS: Effects of Euterpe oleracea Mart. (AÇAÍ) extract in acute lung inflammation induced by cigarette smoke in the mouse. Phytomedicine 19: 262-269, 2012.

19. Zapata-Sudo G, da Silva JS, Pereira SL, Souza PJ, de Moura RS and Sudo RT: Oral treatment with Euterpe oleracea Mart. (açaí) extract improves cardiac dysfunction and exercise intolerance in rats subjected to myocardial infarction. BMC Complement Altern Med 14: 227, 2014.

20. Silva DF, Vidal FC, Santos D, Costa MC, Morgado-Díaz JA, do Desterro Soares Brandão Nascimento $M$ and de Moura RS Cytotoxic effects of Euterpe oleracea Mart. in malignant cell lines. BMC Complement Altern Med 14: 175, 2014.

21. Li D, Guo HZ, Yang CS, Huang AQ and Rong CZ: Modelling the chronic alcoholic liver disease (ALD) in rat and its pathologic observation. Chin J Integrated Traditional And Western Med Liver Dis 10: 2000 (In Chinese)

22. Livak KJ and Schmittgen TD: Analysis of relative gene expression data using real-time quantitative PCR and the 2(-Delta Delta C(T)) method. Methods 25: 402-408, 2001.

23. Altamirano $\mathrm{J}$ and Bataller R: Alcoholic liver disease: Pathogenesis and new targets for therapy. Nat Rev Gastroenterol Hepatol 8: 491-501, 2011.

24. Kang J, Xie C, Li Z, Nagarajan S, Schauss AG, Wu T and Wu X: Flavonoids from acai (Euterpe oleracea Mart.) pulp and their antioxidant and anti-inflammatory activities. Food Chem 128: $152-157,2011$

25. Wu D and Cederbaum AI: Oxidative stress and alcoholic liver disease. Semin Liver Dis 29: 141-154, 2009.

26. Zhou Z, Wang L, Song Z, Lambert JC, McClain CJ and Kang YJ: A critical involvement of oxidative stress in acute alcohol-induced hepatic TNF-alpha production. Am J Pathol 163: 1137-1146, 2003.

27. Zhang N, Li L, Wang P, Sun H, Wu Z, Piao C and Wang X: Pharmacokinetics of the main compounds absorbed into blood after oral administration of Liu Wei Di Huang Wan, a typical combinatorial intervention of Chinese medical formula. J Nat Med 67: 36-41, 2013.

28. Galicia-Moreno M and Gutierrez-Reyes G: The role of oxidative stress in the development of alcoholic liver disease. Rev Gastroenterol Mex 79: 135-144, 2014 (In English, Spanish)

29. Li G, Ye Y, Kang J, Yao X, Zhang Y, Jiang W, Gao M, Dai Y, Xin Y, Wang Q, et al: 1-Theanine prevents alcoholic liver injury through enhancing the antioxidant capability of hepatocytes. Food Chem Toxicol 50: 363-372, 2012.

30. Wu JW, Wang SP, Alvarez F, Casavant S, Gauthier N, Abed L, Soni KG, Yang G and Mitchell GA: Deficiency of liver adipose triglyceride lipase in mice causes progressive hepatic steatosis. Hepatology 54: 122-132, 2011.
31. de Oliveira PR, da Costa CA, de Bem GF, Cordeiro VS, Santos IB, de Carvalho LC, da Conceição EP, Lisboa PC, Ognibene DT, Sousa PJ, et al: Euterpe oleracea Mart.-derived polyphenols protect mice from diet-induced obesity and fatty liver by regulating hepatic lipogenesis and cholesterol excretion. PLoS One 10: e0143721, 2015.

32. Gheita TA and Kenawy SA: Measurement of malondialdehyde, glutathione, and glutathione peroxidase in SLE patients. Methods Mol Biol 1134: 193-199, 2014

33. McCord JM and Edeas MA: SOD, oxidative stress and human pathologies: A brief history and a future vision. Biomed Pharmacother 59: 139-142, 2005.

34. Chakraborty I, Kunti S, Bandyopadhyay M, Dasgupta A, Chattopadhyay GD and Chakraborty S: Evaluation of serum zinc level and plasma SOD activity in senile cataract patients under oxidative stress. Indian J Clin Biochem 22: 109-113, 2007.

35. Balasubramaniyan V, Kalaivani Sailaja J and Nalini N: Role of leptin on alcohol-induced oxidative stress in Swiss mice. Pharmacol Res 47: 211-216, 2003.

36. Lee WS, McKiernan PJ and Kelly DA: Serum ferritin level in neonatal fulminant liver failure. Arch Dis Child Fetal Neonatal Ed 85: F226, 2001.

37. Ananian P, Hardwigsen J, Bernard D and Le Treut YP: Serum acute-phase protein level as indicator for liver failure after liver resection. Hepatogastroenterology 52: 857-861, 2005.

38. Li W, Liu Y, Wang Z, Han Y, Tian YH, Zhang GS, Sun YS and Wang YP: Platycodin D isolated from the aerial parts of Platycodon grandiflorum protects alcohol-induced liver injury in mice. Food Funct 6: 1418-1427, 2015.

39. Chen YL, Peng HC, Hsieh YC and Yang SC: Epidermal growth factor improved alcohol-induced inflammation in rats. Alcohol 48: 701-706, 2014.

40. Suk KT, Kim MY and Baik SK: Alcoholic liver disease: Treatment. World J Gastroenterol 20: 12934-12944, 2014.

41. Zhao XQ, Liang B, Liu Y and Huang XQ: Agaricoglycerides protect against hepatic ischemia/reperfusion injury by attenuating inflammatory response, oxidative stress, and expression of NF-kB. Evid Based Complement Alternat Med 2015: 142736 , 2015.

42. Ruiz-Miyazawa KW, Zarpelon AC, Pinho-Ribeiro FA, Pavão-de-Souza GF, Casagrande R and Verri WA Jr: Vinpocetine reduces carrageenan-induced inflammatory hyperalgesia in mice by inhibiting oxidative stress, cytokine production and NF- $\kappa \mathrm{B}$ activation in the paw and spinal cord. PLoS One 10: e0118942, 2015.

43. Matyja E, Taraszewska A and Marszalek P: Necrosis and apoptosis of tumor cells in embolized meningiomas: Histopathology and P53, BCL-2, CD-68 immunohistochemistry. Folia Neuropathol 37: 93-98, 1999.

44. Yan SL, Yang HT, Lee HL and Yin MC: Protective effects of maslinic acid against alcohol-induced acute liver injury in mice. Food Chem Toxicol 74: 149-155, 2014.

(i) 9 This work is licensed under a Creative Common Attribution-NonCommercial-NoDerivatives 4.0 International (CC BY-NC-ND 4.0) License. 